\title{
A Saúde nos Documentos Curriculares Oficiais para o Ensino de Ciências: da Lei de Diretrizes e Bases da Educação à Base Nacional Comum Curricular
}

\author{
Health in the Official Curricular Documents for the Teaching \\ of Sciences: from the National Education Guidelines and \\ Framework Law to the National Common Curricular Base
}

\author{
Marta Caires de Sousa ${ }^{(1)}$ Brasil \\ Ana Paula Miranda Guimarães (1) Brasil \\ Amanda Amantes (i) Brasil
}

Este artigo discute as concepções de saúde expressas nos documentos curriculares oficiais brasileiros para a área das Ciências da Natureza, considerando como elementos centrais os conhecimentos científicos $(\mathrm{K})$, os valores $(\mathrm{V})$ e as práticas sociais $(\mathrm{P})$ apresentados nos textos. Trata-se de uma análise documental, que utilizou a Análise de Conteúdo como principal referencial metodológico e saúde como unidade temática. Os resultados apontaram que um conceito mais amplo de saúde é pouco explorado nos documentos referenciais. Ou seja, o entendimento sobre saúde abordado nos diferentes documentos está fortemente relacionado ao conhecimento do corpo humano e aos comportamentos saudáveis, as práticas propostas direcionam para os cuidados pessoais e os valores mais prevalentes correspondem à noção de autonomia e protagonismo. Observa-se que predomina uma concepção de saúde pautada no funcionamento do corpo humano, na doença, nos hábitos e comportamentos considerados adequados para manter a saúde. $\mathrm{O}$ "direito à saúde" e "políticas públicas de saúde" são categorias pouco manifestas, o que demonstra a necessidade de ampliar a concepção de saúde nos documentos analisados.

Palavras-chave: Concepções de saúde; Educação em saúde; Documentos curriculares; Modelo KVP.

This paper reports a study about health conceptions in official Brazilian curricular documents on the Natural Sciences field, taking as central concepts the scientific knowledge $(\mathrm{K})$, the values $(\mathrm{V})$ and the social practices $(\mathrm{P})$ presented in the texts. It is a documentary analysis that used the Content Analysis as the main methodological reference and health as thematic unit. The results showed that a broader concept of health is poorly explored in the reference documents. That is, the understanding about health addressed in the different documents is strongly related to the knowledge of the human body and to healthy behaviors, the proposed practices direct towards personal care 
and the most prevalent values correspond to the notion of autonomy and protagonism. There is a general conception of health related with human body functioning, disease and habits/behaviors concerning health adequate maintenance. Categories as "right to health" and "public health policies" are not well-considered in the documents, therefore, findings point to the need for a broader discussion to be taken into account in these documents.

Keywords: Health conceptions; Health education; Curricular documents; Model KVP.

\section{Introdução}

Saúde é um tema relevante que está relacionado com o desenvolvimento técnico científico das sociedades, da própria existência humana e tem ocupado de forma crescente as pautas e discussões em diversos espaços. No contexto escolar, por exemplo, trata-se de uma temática que historicamente tem sido abordada, sendo que uma das formas de organização e inserção desse assunto nos processos de ensino e de aprendizagem é por meio do currículo formal.

Após a promulgação da Lei de Diretrizes e Bases da Educação (LDB) (Lei n. 9.394, 1996), outros documentos curriculares oficiais foram publicados com a finalidade de orientar a organização e o desenvolvimento dos currículos de todas as redes de ensino da Educação Básica do país. Eles apontam uma série de conhecimentos, princípios, valores, atitudes e ações que devem ser desenvolvidos nos contextos escolares. Neste artigo, referente ao tema saúde, serão analisados os Parâmetros Curriculares Nacionais (PCN) (MEC, 1998, 1998b); as Diretrizes Curriculares Nacionais (DCN) (MEC, 1998c), as Orientações Curriculares para o Ensino Médio (OCEM) (MEC, 2006) e a Base Nacional Comum Curricular (BNCC) e suas versões (MEC, 2015, 2016, 2017a, 2017b, 2018).

Os PCN, documento de caráter não obrigatório, trouxeram uma série de orientações para organizar os currículos. A saúde é apresentada como um dos Temas Transversais (TT) em uma das publicações dos PCN além de estar presente nos conteúdos previstos para a área das Ciências da Natureza, seja para o Ensino Fundamental (MEC, 1998b) ou para o Ensino Médio (MEC, 1999, 2002).

As DCN para o Ensino Fundamental reportam a saúde como parte da formação cidadã. Em 2013, as novas DCN, apresentadas como Diretrizes Curriculares Nacionais da Educação Básica (DCNEB), contendo normas obrigatórias para essa etapa da escolarização, ressaltam a saúde como um campo do conhecimento que deve estar contemplado nas diferentes áreas do conhecimento. As OCEM, publicadas em 2006, no que se refere à área de Ciências da Natureza, Matemática e suas Tecnologias, destacam a saúde como um tema relevante, especialmente nos conteúdos relacionados à Biologia. A partir de 2015, o Ministério da Educação (MEC) publicou as versões preliminar e final da BNCC. O documento, em sua versão final, tem a intenção de ser um referencial curricular obrigatório para todas as instituições de ensino brasileiras. Na primeira versão, 
a saúde apareceu inserida nos Direitos de Aprendizagem, enquanto que na versão final para a Educação Infantil e o Ensino Fundamental ela está diluída em algumas habilidades previstas para certos componentes curriculares.

A presença do tema saúde nesses documentos orientadores da Educação Básica indica que a temática assume uma dimensão importante a ser trabalhada no processo de ensino e de aprendizagem em todas as suas etapas. Tomando como exemplo as DCNEB, estas destacam que "a fonte em que residem os conhecimentos escolares são as práticas socialmente construídas e que se constituem em âmbitos de referência dos currículos, essas práticas correspondem, também, ao campo da saúde” (MEC, 2013, p. 23-24).

Os documentos curriculares trazem orientações para que os currículos escolares se organizem a partir de áreas do conhecimento, visando maior integração e interdisciplinaridade entre os componentes curriculares que compõem cada área. Neles, as Ciências da Natureza representam a área em que tradicionalmente são discutidos os conteúdos que se relacionam com a saúde, fundamentalmente, os componentes Ciências, no Ensino Fundamental, e Biologia, no Ensino Médio. A concentração do debate da saúde nestes dois componentes é alvo de muitas críticas, visto que se trata de um tema transversal, o qual deveria estar contemplado em todos os demais componentes curriculares.

Pesquisas sobre a relação saúde e documentos curriculares no Brasil foram publicadas nos últimos anos (Mohr, 2009; Bomfim et al., 2013; Marinho et al., 2015). Estes autores destacam que há predomínio de enfoque na doença, nos comportamentos considerados saudáveis e nos aspectos biológicos do processo de adoecimento, além de possuir um caráter prescritivo, como destacou Mohr (2009). Entretanto, tais estudos, em sua maioria, restringiram a análise aos PCN TT Saúde, ao componente curricular Ciências e ao nível do Ensino Fundamental. Esse fato indica a carência de estudos sobre saúde que abranjam os demais documentos curriculares, outros componentes para além de Ciências, assim como o nível do Ensino Médio. Desse modo, esta pesquisa pretende suprir parte dessa lacuna, analisando os documentos curriculares da área Ciências da Natureza e seus respectivos componentes curriculares no Ensino Fundamental II e no Ensino Médio.

A apresentação e as orientações epistemológica e metodológica do tema saúde no currículo formal expressa determinada concepção de saúde. Para interpretar a concepção de diferentes atores do sistema educacional, de materiais didáticos e de políticas curriculares, Clément (2006) propõe analisar as interações existentes entre o conhecimento científico (Knowledge $=\mathrm{K}$ ), os sistemas de valores (Values $=\mathrm{V}$ ) e as práticas sociais dos sujeitos (Practice $=\mathrm{P})$. A existência de correlação entre a presença de conhecimentos científicos, os valores expressos e as práticas sociais é um dos pressupostos do modelo KVP, o qual tem sido utilizado para análise de concepções, dentre elas as relacionadas à saúde (Clément, 2006, 2010; Carvalho, \& Clément, 2007).

Nesse sentido, considerando os documentos curriculares oficiais existentes a partir da LDB de 1996, em especial aqueles voltados para as Ciências da Natureza, 
o presente artigo tem por objetivo identificar e caracterizar as concepções de saúde expressas em tais textos, tomando como referencial para a análise o modelo KVP. Eles expressam determinada visão de mundo e estruturam o conhecimento científico, além de representarem um campo de disputa. Além disso, foram formulados em contextos políticos distintos e em um período da história do Brasil em que a saúde, do ponto de vista legal, passou a ser um direito de todos e um dever do Estado. Por isso, acreditamos que a análise proposta neste artigo pode contribuir para discussões e reflexões acerca desse conteúdo e fazer apontamentos a serem considerados para a proposição de abordagens do tema nos contextos de ensino.

\section{O currículo formal - expressão dos conhecimentos, dos valores e das práticas sociais}

O currículo é um lugar, um território, e representa uma relação de poder (Silva, 2010), além de refletir o contexto de determinado momento histórico e as relações políticas e sociais nele existente (Apple, 2006). O currículo também representa um meio de construção e de seleção de determinadas ideias e conhecimentos que prevalecem sobre outras (Lopes, 2004; Lopes, \& Macedo, 2011). Para Apple (2006), tanto a construção como a seleção curricular não são neutras, mas buscam assegurar certa ordem estabelecida.

Existem debates em torno das lacunas existentes entre as políticas curriculares, documentos planificados e escritos e o currículo praticado; ou seja, é preciso refletir o tema levando em consideração o currículo prescrito ou formal e o currículo vivido ou em ação (Lopes, 2004; Macedo, 2006). Macedo (2006) considera que há um saber externo à escola que é transmitido via currículo, percebido como o currículo como fato, que estrutura determinado conhecimento e seleciona saberes e culturas como objetos de ensino. O currículo como fato apresenta-se constituído por conhecimentos formalizados, instituídos científica e historicamente, influenciados por condicionantes políticos, econômicos e sociais e representa o que deve ser ensinado nas escolas. De acordo com Lopes (2004), toda política curricular representa

Um processo de seleção e de produção de saberes, de visões de mundo, de habilidades, de valores, de símbolos e significados, portanto, de culturas capazes de instituir formas de organizar o que é selecionado, tornando-o apto a ser ensinado (Lopes, 2004, p. 111).

Ainda de acordo com esta autora, o currículo é um espaço conflituoso de produção de cultura, de embates de ideias, representa formas de entender e de construir o conhecimento. Portanto, um currículo expressa determinada concepção de mundo.

Por concepção, podemos considerar as proposições de Clément $(2006,2010)$. O autor admite que a concepção se relaciona com o saber, com as representações sociais e mentais, as crenças, as ideologias e o fazer de cada sujeito. Ainda, ele considera que a concepção emerge a partir da interação entre os conhecimentos científicos $(\mathrm{K})$, os sistemas de valores $(\mathrm{V})$ e as práticas sociais $(\mathrm{P})$. Sendo assim, os valores e práticas influenciam os conhecimentos ensinados ou propostos para serem ensinados, bem como os conhecimentos influenciam os valores e as práticas sociais dos sujeitos. A interação, 
então, é descrita por três polos: Conhecimentos, Valores e Práticas (Clément, 2006).

O conhecimento diz respeito ao científico, aquele advindo das comunidades científicas. Entretanto, o autor considera que nesse polo também prevalece o conhecimento de cada um, mesmo não tendo um caráter científico. Os valores representam opiniões, crenças e ideologias. Hodson (2003) afirma que os valores sociais sustentam os desenvolvimentos científico e tecnológico, e Clément (2010) acrescenta que os poderes econômico e político desempenham um papel decisivo nos sistemas de valores, assim como os valores relacionados à própria ciência e ao seu grau de verdade. As práticas sociais representam as práticas dos sujeitos, que no sistema educacional são os professores, legisladores, ministros da educação, autores de livros, de currículos, de manuais, dentre outros. Cada um dos elementos influencia e é influenciado pelos demais.

Ao considerar que o currículo, como construção histórica, cultural, política e social, representa uma agregação de conhecimentos estruturados, intencionalmente selecionados, compostos por normas, práticas e valores de determinados sujeitos, o modelo KVP, utilizado no presente estudo, representa um quadro conceitual bastante elucidativo ao apontar características do saber a ser ensinado desde a perspectiva epistemológica, aos valores e às práticas sociais referenciadas.

\section{A saúde no currículo formal}

Saúde é um termo polissêmico e que carrega em si múltiplos sentidos. Do ponto de vista individual e coletivo, adquire significados objetivos e subjetivos em distintos contextos. Nessa perspectiva, Almeida-Filho (2011) ressalta que é preciso considerar a existência não de uma, mas de várias "saúdes". Devido à polissemia do termo, as concepções de saúde são multifacetadas. Entretanto, elas podem ser caracterizadas utilizando como pressuposto os conhecimentos, os valores e as práticas sociais.

A saúde é uma questão fortemente relacionada com aspectos macro e micro estruturais de determinada sociedade. Tais aspectos estão diretamente envolvidos com as condições de vida das pessoas e suas experiências pessoais (Almeida-Filho, 2011; Buss, 2012; Paim, 2012). Uma compreensão mais ampla de saúde, que considera os fatores sociais, econômicos e culturais de uma sociedade, entende que a saúde é fruto da produção e reprodução social, visto que as maneiras pelas quais as sociedades identificam as necessidades e os problemas de saúde buscam explicação e se organizam para enfrentá-los, variam historicamente e dependem de distintos determinantes e condicionantes (Paim, 2006, 2008).

O conceito ampliado de saúde, que surgiu em 1948 com a definição adotada pela Organização Mundial da Saúde (OMS), ao incorporar à dimensão biológica, a mental e social, procurou romper com a lógica reducionista de conceber saúde apenas voltada aos aspectos biológicos e ao processo de adoecimento dos órgãos do corpo. Na perspectiva de ampliar a dimensão social, no Brasil, a VIII Conferência Nacional de Saúde (CNS) (MS, 1986), realizada no ano de 1986, em seu relatório final, incluiu no conceito de 
saúde a alimentação, habitação, educação, renda, meio ambiente, trabalho, transporte, emprego, lazer, liberdade, acesso e posse da terra e acesso a serviços de saúde como condições necessárias para se garantir a saúde. A partir de então, a saúde passou a ser uma conquista social e um direito de cidadania.

A compreensão de saúde expressa pela VIII CNS direcionou a formulação do conceito de saúde apresentado na Constituição Federal Brasileira (CFB) de 1988 (Constituição Federal de 1988, 1988) e na Lei Orgânica da Saúde (Lei n. 8080, 1990). A CFB de 1988, no artigo 196 refere que

A saúde é direito de todos e dever do Estado, garantido mediante políticas sociais e econômicas que visem à redução do risco de doença e de outros agravos e ao acesso universal e igualitário às ações e serviços para sua promoção, proteção e recuperação (Constituição Federal de 1988, 1988, p. 153).

No currículo formal, conceber saúde em seu sentido amplo representa reconhecer as inter-relações existentes entre o desenvolvimento científico e o tecnológico e os aspectos sociais, políticos, econômicos e culturais que influenciam as condições de saúde. Representa apontar a complexidade do tema e indicar a criação e a implementação de estratégias para que o ensino fomente o desenvolvimento humano com equilíbrio, sustentabilidade e equidade.

Monteiro e Bizzo (2014) consideram que nos currículos escolares a saúde pode expressar diferentes concepções, bem como diferentes compreensões dos fatores que influenciam ou determinam o processo saúde e doença, uma vez que tais diferenças se expressam por distintas visões de mundo, de sociedade e do ser humano. Um estudo desenvolvido por Carvalho et al. (2008) sobre as concepções de educação em saúde de professores de diferentes países, identificaram, dentre outros aspectos, que a concepção de saúde contida nos manuais dos sistemas educacionais influenciava a concepção de educação em saúde expressa pelos professores em exercício. Esse fato colabora com o entendimento de que os currículos prescritos podem não determinar, mas exercem influências sobre as práticas pedagógicas nos contextos educacionais.

Os resultados de algumas análises do tema saúde no currículo formal da Educação Básica mostram que o assunto teve destaque como tema transversal nos PCN, mas esse mesmo destaque não se conservou e nem se desenvolveu em outros documentos curriculares (Bomfim, et al., 2013; Marinho et al., 2015). Nos PCN, a ênfase dada à saúde diz respeito aos aspectos biológicos de funcionamento do corpo, à prevenção de doenças e aos hábitos e atitudes tidos como saudáveis (Bomfim; 2013; Venturi, \& Mohr, 2013; Barbi, \& Megid Neto, 2017). Mesmo limitado, o direito à saúde aparece relacionado à noção de cidadania, o que, segundo Bomfim et al. (2013), no máximo, indica um entendimento do direito, mas não a sua materialização. Esses autores reafirmam a importância do tema nos currículos oficiais e ressaltam a necessidade de promover uma discussão mais ampla e crítica. 


\section{Metodologia}

Trata-se de uma pesquisa empírica com procedimento de análise documental, referente às concepções de saúde expressas nos documentos curriculares nacionais para a área de Ciências da Natureza, estabelecendo como marco inicial a LDB de 1996 até a última versão da BNCC para o Ensino Médio, publicada em abril de 2018. O período proposto parte do princípio de que se trata de um processo histórico marcado por mudanças conjunturais e políticas com possibilidades de alcançar diferentes apontamentos quanto à abordagem da saúde no contexto da Educação Básica e do Ensino de Ciências.

Para compor o corpus da análise, foram selecionados 13 documentos, os quais constam na Figura 1. Todos eles estão disponíveis na forma virtual no site do MEC. A seleção do corpus seguiu alguns critérios propostos por Bardin (2009):

1 - Homogeneidade: todos são documentos oficiais e orientam a organização curricular das escolas;

2 - Representatividade: são publicações que indicam os princípios, os objetivos, os conhecimentos, valores e práticas para a educação escolar e citam a saúde como parte destes;

3 - Exaustividade: representam o universo das publicações no período definido;

4 - Pertinência: são fontes de informações adequadas e correspondem ao objetivo da análise.

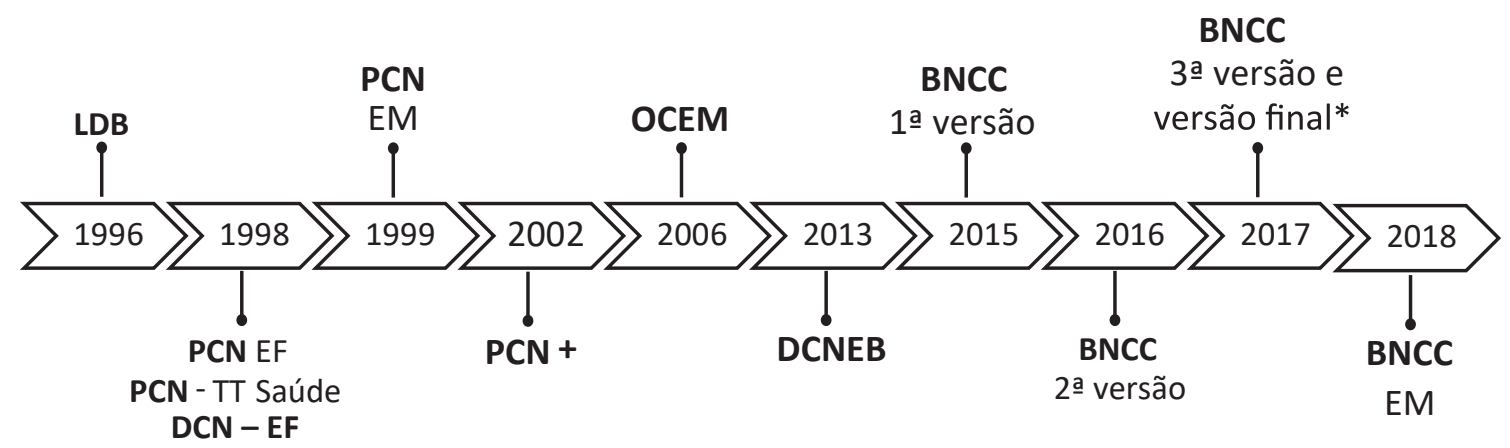

Siglas: $\mathrm{BNCC}=$ Base Nacional Comum Curricular; $\mathrm{CN}=$ Ciências da Natureza; $\mathrm{DCN}=$ Diretrizes Curriculares Nacionais; EB = Educação Básica; EF = Ensino Fundamental; EM = Ensino Médio; LDB = Lei de Diretrizes e Bases; OCEM = Orientações Curriculares para o Ensino Médio; PCN = Parâmetros Curriculares Nacionais; TT $=$ Tema Transversal. * Versão final para a Educação Infantil e o Ensino Fundamental.

Figura 1. Relação de documentos utilizados na análise

A técnica de análise está ancorada nas proposições de Bardin (2009), que incluem as fases de pré-análise, exploração do material, tratamento dos resultados com as respectivas inferências e interpretações. A análise temática considerou como unidade de registro a palavra-chave "saúde" presente nos documentos. Realizou-se o recorte dos textos em unidades de contexto e em seguida o seu reagrupamento, permitindo a 
realização de uma síntese, interpretações e inferências sobre os significados atribuídos ao termo. Como a presença da palavra saúde foi critério de inclusão, as DCN de 1998 para o Ensino Médio foram excluídas do corpus por ausência do termo. Para identificar e selecionar a unidade de registro nos textos, recorreu-se ao comando "Ctrl+F" disponível nos teclados de computadores que possuem o programa Windows.

A partir da exploração do material que compôs o corpus, houve uma organização detalhada de cada unidade de contexto e do seu reagrupamento, procedendo sucessivas leituras a fim de identificar o que os textos dizem sobre saúde, se conceituam e como conceituam o termo, as formas de cuidados abordadas e as responsabilidades para com a saúde.

Com base nos sentidos atribuídos aos enunciados, cada unidade de contexto foi codificada e transcrita para uma planilha, a qual se constitui como um livro de códigos. Para cada código foi estabelecida uma categoria. Devido à característica plural de alguns enunciados, no processo de categorização alguns códigos tiveram categorias principais e categorias secundárias. E para alcançar um refinamento das categorias, o livro de códigos passou por sucessivas revisões até atingir a interpretação final. As categorias formuladas emergiram a partir das leituras sistemáticas dos textos e foram selecionadas por ser as mais frequentes e mais evidentes em cada documento. As categorias eleitas estão expressas na figura 2.

Para a identificação e caracterização das concepções de saúde foi considerado o modelo KVP (Clément, 2006, 2010), a partir de três polos: conhecimentos propostos, valores implícitos e explícitos e as práticas sociais indicadas. Sobre saúde, utilizou-se como referência o conceito ampliado proposto pela Organização Mundial de Saúde (WHO, 1948), pela VIII Conferência Nacional de Saúde (MS, 1986) e pela Constituição Federal Brasileira de 1988 (Constituição Federal de 1988, 1988).

\section{Resultados e discussões}

Os documentos analisados servem como referências curriculares para a Educação Básica. Considerando a amplitude desse nível educacional, foi necessário fazer ajustes, e para fins desta pesquisa o recorte feito considerou para análise os textos das orientações gerais de cada documento e os textos das orientações específicas voltadas para a área Ciências da Natureza, focalizando os componentes curriculares "Ciências" no Ensino Fundamental II, "Biologia”, "Física” e "Química”, no Ensino Médio.

A Figura 2 traz a relação dos documentos analisados, o ano de publicação, uma breve descrição da finalidade, a frequência do termo saúde e as categorias mais frequentes em cada documento. 


\begin{tabular}{|c|c|c|c|c|}
\hline Documento & Ano & Finalidade & $\begin{array}{l}\text { Frequência } \\
\text { do termo }\end{array}$ & $\begin{array}{l}\text { Categorias mais } \\
\text { frequentes }\end{array}$ \\
\hline $\begin{array}{l}\text { LDB - Lei } \\
9.394 / 96\end{array}$ & 1996 & $\begin{array}{l}\text { Estabelecer as Diretrizes e Bases da } \\
\text { Educação Nacional }\end{array}$ & 1 & Assistência à saúde \\
\hline $\mathrm{DCN}-\mathrm{EF}$ & 1998 & $\begin{array}{l}\text { Estabelecer as Diretrizes Curriculares } \\
\text { Nacionais para o Ensino Fundamental }\end{array}$ & 1 & $\begin{array}{l}\text { Saúde articulada à } \\
\text { educação e à vida } \\
\text { cidadã }\end{array}$ \\
\hline $\mathrm{PCN}-\mathrm{CN}$ & 1998 & $\begin{array}{l}\text { Estabelecer as Referências Nacionais } \\
\text { Comuns para o Ensino das Ciências } \\
\text { Naturais }\end{array}$ & 93 & $\begin{array}{l}\text { Saúde como estado } \\
\text { de equilíbrio } \\
\text { dinâmico do corpo }\end{array}$ \\
\hline $\begin{array}{l}\text { PCN - TT } \\
\text { Saúde }\end{array}$ & 1998 & $\begin{array}{l}\text { Apresentar a saúde como um Tema } \\
\text { Transversal }\end{array}$ & 261 & $\begin{array}{l}\text { Educação para a } \\
\text { saúde }\end{array}$ \\
\hline PCN - EM & 1999 & $\begin{array}{l}\text { Apresentar os Parâmetros Curriculares } \\
\text { Nacionais para o Ensino Médio }\end{array}$ & 12 & $\begin{array}{l}\text { Degradação } \\
\text { ambiental e agravos à } \\
\text { saúde humana }\end{array}$ \\
\hline $\mathrm{PCN}+$ & 2002 & $\begin{array}{l}\text { Apresentar Orientações Curriculares } \\
\text { complementares aos PCN }\end{array}$ & 43 & $\begin{array}{l}\text { Saúde e as condições } \\
\text { de vida das pessoas }\end{array}$ \\
\hline OCEM & 2006 & $\begin{array}{l}\text { Apresentar sugestões para as práticas } \\
\text { pedagógicas e organização dos } \\
\text { currículos do Ensino Médio }\end{array}$ & 10 & Ambiente e saúde \\
\hline DCNEB & 2013 & $\begin{array}{l}\text { Estabelecer Orientações Nacionais para } \\
\text { a Educação Básica }\end{array}$ & 100 & $\begin{array}{l}\text { Saúde como campo } \\
\text { de conhecimento e de } \\
\text { serviços }\end{array}$ \\
\hline $\begin{array}{l}\text { BNCC } \\
1^{\text {a }} \text { versão }\end{array}$ & 2015 & $\begin{array}{l}\text { Estabelecer uma Base Nacional Comum } \\
\text { para os currículos da Educação Básica } \\
\text { (versão inicial disponibilizada para } \\
\text { consulta pública) }\end{array}$ & 22 & $\begin{array}{l}\text { Cuidado com a } \\
\text { saúde }\end{array}$ \\
\hline $\begin{array}{c}\text { BNCC } \\
2^{\mathrm{a}} \text { versão }\end{array}$ & 2016 & $\begin{array}{l}\text { Estabelecer uma Base Nacional Comum } \\
\text { para os currículos da Educação Básica } \\
\text { (versão elaborada após contribuições da } \\
\text { sociedade) }\end{array}$ & 19 & Ambiente e saúde \\
\hline $\begin{array}{c}\text { BNCC } \\
3^{\mathrm{a}} \text { versão }\end{array}$ & 2016 & $\begin{array}{l}\text { Estabelecer uma Base Nacional Comum } \\
\text { para os currículos da Educação } \\
\text { Básica (versão disponibilizada após } \\
\text { contribuições institucionais) }\end{array}$ & 22 & $\begin{array}{l}\text { Cuidados com a } \\
\text { saúde }\end{array}$ \\
\hline $\begin{array}{l}\text { BNCC } \\
\text { versão final } \\
(\text { EI e EF) }\end{array}$ & 2016 & $\begin{array}{l}\text { Estabelecer uma Base Nacional Comum } \\
\text { para os currículos da Educação Infantil e } \\
\text { do Ensino Fundamental (versão final) }\end{array}$ & 19 & $\begin{array}{l}\text { Cuidados com a } \\
\text { saúde }\end{array}$ \\
\hline $\mathrm{BNCC} \mathrm{EM}^{* *}$ & 2018 & $\begin{array}{l}\text { Estabelecer uma Base Nacional Comum } \\
\text { para os currículos do Ensino Médio }\end{array}$ & 9 & Cuidados com a saúde \\
\hline
\end{tabular}

*Frequência do termo saúde nos textos introdutórios e nos textos referentes à área Ciências da Natureza e seus respectivos componentes curriculares . ${ }^{* *}$ No período de realização deste estudo, a BNCC EM estava em análise no Conselho Nacional de Educação.

Figura 2. Documentos analisados, ano de publicação, finalidade do documento, frequência do termo saúde e categorias mais frequentes 


\section{As "saúdes" nos documentos curriculares}

\section{LDB, DCN e DCNEB}

Assistência à saúde foi uma categoria presente na LDB e nas DCNEB. A assistência prevista nesses documentes refere-se à necessidade de a educação dispor de programas de assistência à saúde dos estudantes. A LDB de 1996 estabeleceu em seu artigo 4, inciso VIII, que

O dever do Estado com a educação escolar pública será efetivado mediante a garantia de atendimento ao educando, no ensino fundamental público, por meio de programas suplementares de material didático-escolar, transporte, alimentação e assistência à saúde (Lei n. 9394, 1996, p.11).

Como consequência da LDB, o atendimento anteriormente previsto apenas para o Ensino Fundamental estendeu-se para todo o ciclo básico. Em 2013, as DCNEB voltam a destacar a necessidade de promover o atendimento ao educando por meio de programas de "assistência à saúde", apesar de ambos os documentos não explicitar qual é o tipo de assistência previsto. O termo "assistência à saúde" pode estar relacionado a uma perspectiva de cuidado integral, compreendendo práticas promocionais, preventivas de cura e de reabilitação, ou algo fragmentado. Nos mais diversos espaços acadêmicos, políticos e de serviços de saúde há um intenso debate sobre as formas de organização dos serviços e das práticas de cuidado em saúde, os chamados modelos de atenção à saúde (Paim, 2012; Fertonani et al., 2015).

A assistência à saúde prevista nos documentos curriculares pode ser vislumbrada tomando como referencial os modelos de atenção à saúde, que, de acordo com Paim (2012, p. 463), podem ser compreendidos como "combinações tecnológicas estruturadas para resolução de problemas e para o atendimento de necessidades de saúde, individuais e coletivas". Nessas combinações, ao tomar como objeto de ação/intervenção a saúde ou a doença, as práticas de cuidado irão de ações pontuais e fragmentadas à integralidade da atenção. Os documentos não detalham sobre a assistência à saúde prevista, como organizá-la e o que se espera como resultados.

As DCNEB indicam que as políticas educacionais serão mais exitosas se articuladas às demais políticas sociais, entre elas a de saúde. Apontam como conhecimentos os cuidados com a saúde, a saúde como campo de conhecimento, como prática e como serviços. Citam a importância da promoção da saúde física e mental, saúde sexual e saúde reprodutiva e prevenção do uso de drogas. Por fim, as DCNEB trazem a saúde na perspectiva de assistência e como um direito atrelado aos demais direitos sociais. As DCN para Ensino Fundamental, em 1988, relacionam a saúde com uma vida cidadã com apenas uma citação da palavra, não promovendo discussão nem reflexão em torno do tema.

Os valores expressos nesses documentos e que estão relacionados com a saúde são a parceria, a cidadania e o direito à saúde. Clément (2006) considera que os sistemas 
de valores estão relacionados a opiniões, crenças, princípios e ideologias. Assim, considerando os valores na interação KVP, nestes documentos destacam princípios coletivos que orientam escolhas e atitudes com vistas à formação cidadã.

\section{PCN - TT Saúde, PCN Ciências Naturais (EF II), PCNEM, PCN+}

A análise dos PCN pode identificar que nestes documentos a saúde assume diferentes definições. Os PCN TT Saúde, por exemplo, voltam-se para uma abordagem epistemológica do processo saúde e doença; consequentemente, discutem que o conhecimento da saúde deve ser pautado por um conceito dinâmico e multideterminado, problematizando a polissemia do termo. Fazem diversas menções acerca da importância da "Educação para a Saúde", afirmando que esta "pode cumprir papel destacado ao favorecer o processo de conscientização quanto ao direito à saúde e aos condicionantes do processo saúde doença" (MEC, 1998b, p. 12). Metodologicamente, eles apontam ações educativas voltadas para práticas de prevenção de doenças, riscos e agravos, destacam a necessidade dos cuidados com a saúde e descrevem estratégias para a promoção da saúde. De maneira superficial, mencionam a saúde como um direito e o Sistema Único de Saúde (SUS) como política pública de saúde.

Educação para a saúde é uma categoria bastante enfatizada nestes PCN. Esta categoria surge a partir de uma confluência dos termos educação e saúde, sendo relacionada com conhecimentos, princípios, práticas e comportamentos direcionados à saúde. Valadão (2004) ressalta que há uma clara distinção entre educação em saúde e educação para a saúde. Para a autora, educação para a saúde estaria mais atrelada às informações sobre autocuidado e comportamentos tidos como saudáveis, enquanto que a educação em saúde enfatiza a participação do cidadão em processos de acesso e gestão de serviços de saúde, além de agregar experiências educativas e conhecimentos acerca da saúde. Para Mohr (2002), a educação em saúde se destaca com um campo de trabalho e exercício pedagógico, enquanto a educação para a saúde se refere a uma meta fixada que deverá ser atingida. Apesar de no aspecto teórico existir a demarcação dos termos, no exercício das práticas pedagógicas conciliam-se os discursos em torno de mudanças de hábitos individuais e estilos de vida para ter e manter a saúde.

Já nos PCN Ciências Naturais para o Ensino Fundamental II, os conhecimentos sobre saúde, organizados em habilidades e competências, focam a compreensão dos aspectos biológicos de funcionamento do corpo humano. Os conteúdos eleitos para trabalhar o tema enfatizam os fatores orgânicos, os processos patológicos, os comportamentos individuais tidos como adequados, especialmente os hábitos alimentares e o "equilíbrio dinâmico do corpo humano" como condição necessária para ter saúde. Percebe-se um forte viés comportamentalista voltado ao entendimento sobre as práticas de prevenção de doenças e de riscos. Por sua vez, nos PCN para o Ensino Médio, tanto no texto das bases legais, como nos textos direcionados para as Ciências da Natureza, a saúde é associada ao corpo humano e ao meio ambiente, destacando a degradação ambiental e seus efeitos na saúde, porém sem maiores discussões. O tema 
está presente nas habilidades e competências previstas para Biologia e ausente naquelas previstas para Química e Física.

Nos PCN+, é reforçado o entendimento da saúde associada aos cuidados com o corpo, ao funcionamento dos órgãos e dos sistemas e atrelada às diversas doenças. Ao mesmo tempo, este documento enfatiza que a Biologia deve trabalhar a questão da saúde como algo que não se restringe à ausência de doenças, devendo relacioná-la com as condições de vida das populações, sendo fundamental abordar a distribuição desigual da saúde nas populações humanas e discutir o "perfil de saúde do brasileiro com ênfase nos contrastes regionais e locais" (MEC, 2002, p. 44). A partir desta perspectiva, os PCN + lançam um olhar para além do biológico, embora a grande ênfase dada seja nos aspectos biológicos do funcionamento do corpo humano. Na Física, a saúde é abordada somente na compreensão entre as radiações e seus efeitos na saúde humana, enquanto na Química são estabelecidas correlações da saúde com a poluição ambiental, especialmente pela queima dos combustíveis fósseis.

De modo geral, nesses documentos os conhecimentos destacados se relacionam com os cuidados pessoais para obter uma vida saudável; o corpo humano; os processos de adoecimento e as relações entre saúde, meio ambiente e qualidade de vida. As práticas indicadas estão relacionadas com a prevenção de doenças, de riscos e agravos e destacam a importância de estratégias para a promoção da saúde. Os valores referemse ao respeito para com a saúde individual e coletiva e ao protagonismo dos estudantes para cuidar da sua saúde.

Embora os PCN TT situem a saúde numa perspectiva ampliada ao discorrer sobre o conceito, nas recomendações dos conteúdos e das metodologias percebe-se uma abordagem limitada, biológica e individualizada, mostrando certa contradição ao abordar o tema. O enfoque biológico da saúde expresso nos PCN TT Saúde e Ciências Naturais já foi apontado por outros estudos (Bomfim et al., 2013; Mohr, 2009; Venturi, \& Mohr, 2013). Esses autores criticam a demasiada ênfase dada ao desenvolvimento de hábitos, atitudes e comportamentos considerados saudáveis que, para os autores, contradiz com a ideia de educação voltada para a cidadania, tal qual expressa pela LDB. Assim, eles indicam a necessidade de superação da abordagem tradicional do corpo humano e das doenças. Bomfim et al. (2013) também frisam que os PCN que tratam a saúde como tema transversal, por responsabilizar em demasia o indivíduo, promovem uma cidadania passiva com um tipo de educação voltada à conformação e não com viés para transformação da realidade posta.

\section{As OCEM}

As OCEM para o ensino das Ciências da Natureza afirmam de forma explícita que "compete ao ensino da Biologia, prioritariamente, o desenvolvimento de assuntos ligados à saúde, ao corpo humano, à adolescência e à sexualidade" (MEC, 2006, p. 24). Neste documento, a saúde é apresentada de forma bem limitada, como algo genérico em apenas dez citações do termo. Não há discussão conceitual sobre o tema e 
disponibilizam pouca indicação metodológica acerca das possibilidades de trabalhá-lo na prática pedagógica. Tal documento propõe conhecimentos sobre "definições sobre saúde e doença" e os "indicadores de saúde pública". Como práticas, os alunos podem investigar sobre a distribuição desigual dos serviços de saúde e os fatores associados a esse problema, aspectos considerados como favoráveis ao desenvolvimento da autonomia desses sujeitos.

$\mathrm{Na}$ Biologia, é proposta uma discussão sobre o agronegócio e transgênicos. $\mathrm{Na}$ Química, o tema saúde é considerado pertinente no processo de formação, porém sem detalhamentos. Na Física, o tema não é mencionado. Os valores implícitos correspondem à autonomia, ao protagonismo estudantil e ao respeito em relação à saúde.

\section{A BNCC e suas versões}

Nas versões da BNCC, a saúde é um tema pouco explorado. De maneira geral, todas as versões associam conhecimentos, práticas e valores aos cuidados necessários para ter saúde. "Cuidados com a saúde" é uma categoria muita enfatizada e que por diversas vezes aparece explícita e implícita nos textos da BNCC. Nas três primeiras versões da Base, a saúde é apontada como um tema que deve ser discutido pelas Ciências da Natureza de forma transversal e contextualizada, favorecendo o protagonismo dos estudantes. Na última versão, para os anos finais do Ensino Fundamental, o documento retoma as perspectivas dos PCN e aponta a saúde como um equilíbrio dinâmico do corpo, relacionando-a aos cuidados considerados saudáveis.

Na primeira versão da Base, nos princípios orientadores, relacionados ao direito à educação, o texto destaca que os estudantes podem "cuidar e se responsabilizar pela saúde e bem-estar próprios e daqueles com quem convivem" (MEC, 2015, p.7). Além disto, tal documento aponta que, com base nos conhecimentos científicos, os estudantes devem ser preparados para cuidar da sua saúde, o que consiste basicamente em alimentar-se de forma saudável; prevenir-se de viroses; evitar problemas, como a obesidade; prevenir-se de perigos com acidentes elétricos e ter uma responsabilidade coletiva com o desperdício de energia e com o descarte do lixo. Nestas perspectivas, conhecimentos, práticas e valores se articulam.

A segunda versão da Base ressalta que a área das Ciências da Natureza deve envolver a discussão de múltiplas temáticas, entre elas a saúde. Para os anos finais do Ensino Fundamental, curiosamente a palavra saúde não aparece nenhuma vez nos objetivos de aprendizagem propostos. Todavia, nestes há indícios implícitos sobre os conhecimentos esperados, por exemplo, quando prevê que os estudantes possam

Classificar riscos a que se expõem populações humanas, desde secas, erosão, deslizamentos, epidemias, até poluição de águas e do ar, identificando suas causas e efeitos sobre o ambiente e na vida humana (MEC, 2016, p. 443).

$\mathrm{Na}$ terceira versão da Base e na versão finalizada, que não contemplou o Ensino Médio, o texto relativo às competências gerais estimula que os estudantes reconheçamse e cuidem de sua saúde física e emocional e que sejam "protagonistas no autocuidado 
com seu corpo, na perspectiva do cuidado integral à saúde física, mental, sexual e reprodutiva e valorização das experiências pessoais e coletivas" (MEC, 2017, p. 295). Tais versões ainda indicam práticas de pesquisas e de investigações sobre saúde. A versão final da BNCC, publicada no final do ano de 2017, retoma o modelo de habilidades e competências e destaca que, a partir dos conhecimentos científicos, os estudantes poderiam tomar decisões "a respeito da saúde individual e coletiva com base em princípios éticos, democráticos, sustentáveis e solidários”. (MEC, 2017, p. 323).

Nas versões da BNCC, prevalece uma vertente reducionista da saúde, associando-a a uma abordagem comportamentalista voltada aos cuidados, cuja responsabilidade recai fortemente sobre os indivíduos. Marinho e Silva (2015) observam que, na prática, mudanças comportamentais e de atitudes tão pregadas nas orientações educacionais não têm gerado efeitos, especialmente no que diz respeito à aprendizagem dos estudantes. Esse fato corrobora o debate sobre a necessidade de ampliar as discussões relacionadas à saúde nos documentos curriculares, bem como apontar com clareza as ações concretas que possam ser realizadas pelos diferentes sujeitos que atuam no contexto das escolas.

Para o Ensino Médio, as primeiras versões da BNCC destacam que as Ciências da Natureza têm forte relação com a saúde. Na Biologia, os conhecimentos voltam-se para questões ligadas à sexualidade, endemias, epidemias, à diversidade e interdependência da vida. Na Física, indicam a necessidade de correlacionar a poluição sonora com a saúde, e na Química destacam os conhecimentos acerca do meio ambiente e a saúde, a química dos alimentos e os hábitos alimentares (com destaque para a obesidade e a desnutrição). Estas versões também indicam a necessidade de discussão sobre a produção industrial de alimentos e a saúde. Em abril de 2018, o MEC divulgou a proposta da BNCC para o Ensino Médio. Nesta versão, o que antes era destacado como "Objetivos de Aprendizagens" passou a ser descrito como "Competências Gerais da Educação Básica”. Nestas, a saúde aparece na seguinte descrição "conhecer-se, apreciarse e cuidar de sua saúde física e emocional, compreendendo-se na diversidade humana e reconhecendo suas emoções e as dos outros, com autocrítica e capacidade para lidar com elas" (MEC, 2018, p. 10).

Na Proposta da Base para o Ensino Médio não são apresentados os componentes curriculares, mas sim as áreas de conhecimento. Os conhecimentos previstos estabelecem que os estudantes consigam entender acerca de riscos e cuidados para com a saúde. Como prática, é proposta a formação de observatórios, que consiste em formar grupos de estudantes que elejam um problema que deverá ser acompanhado e analisado. Como exemplo, o documento cita o desenvolvimento de políticas públicas de saúde. Assim, o valor implícito está relacionado à qualidade de vida. Observa-se que, por se tratar de um documento basilar para estruturar os currículos escolares, a saúde é um tema pouco explorado em todas as versões apresentadas. 


\section{Saúde: conhecimento, valores e práticas expressos nos documentos oficiais}

A partir das análises, pode-se realizar uma sistematização dos conhecimentos, dos valores e das práticas que estão explícitas e implícitas em cada documento, nos quais observa-se uma repetição e poucas mudanças e inovações no que concerne à temática saúde. Os textos apresentados abordam a saúde de forma bastante genérica, contêm muitas contradições e dão poucas indicações explícitas para os valores e para as práticas sociais. Os documentos convergem para conhecimentos, práticas e valores semelhantes. A Figura 3 apresenta uma síntese dos principais achados.

\begin{tabular}{|c|c|c|c|c|c|c|}
\hline \multirow{2}{*}{ Conhecimentos $(\mathrm{K})$} & \multicolumn{6}{|c|}{ Documentos } \\
\hline & LDB & $\mathrm{DCN}$ & PCN & OCEM & DCNEB & $\mathrm{BNCC}$ \\
\hline $\begin{array}{l}\text { Saúde - campo de conhecimento, } \\
\text { de práticas e de serviços }\end{array}$ & $-^{*}$ & - & TT; PCN+ & $\mathrm{x}^{* *}$ & $\mathrm{x}$ & $\begin{array}{l}\text { Versões: } 1^{\text {a; }} \text {; } \\
\text { final; EM }\end{array}$ \\
\hline Saúde - condições de vida & - & - & TT; PCN+ & - & - & Versão: $1^{\mathrm{a}}$ \\
\hline $\begin{array}{l}\text { Saúde - corpo humano (sistemas } \\
\text { e órgãos) }\end{array}$ & - & - & PCN EF; EM & $\mathrm{x}$ & - & Todos \\
\hline $\begin{array}{l}\text { Saúde - cuidados e hábitos } \\
\text { saudáveis }\end{array}$ & - & - & Todos & - & $\mathrm{x}$ & Todos \\
\hline Saúde - doenças, riscos e agravos & - & - & Todos & $\mathrm{x}$ & $\mathrm{x}$ & Todos \\
\hline $\begin{array}{l}\text { Saúde - equilíbrio dinâmico do } \\
\text { corpo }\end{array}$ & - & - & PCN EF; TT & - & - & $\begin{array}{l}\text { Versões: } 1^{\mathrm{a}} ; \\
2^{\mathrm{a}} ; 3^{\mathrm{a}}\end{array}$ \\
\hline Saúde - meio ambiente & - & - & $\begin{array}{l}\text { PCN EM; } \\
\text { PCN+ }\end{array}$ & $\mathrm{x}$ & - & $\begin{array}{l}\text { Versões: } 1^{\mathrm{a}} ; \\
2^{\mathrm{a}} ; \mathrm{EM}\end{array}$ \\
\hline Saúde - produção de alimentos & - & - & $\mathrm{PCN}+$ & - & - & EM \\
\hline Prevenção e Promoção da saúde & - & - & Todos & - & - & Todos \\
\hline Valores (V) & LDB & DCN & PCN & OCEM & DCNEB & BNCC \\
\hline Autonomia & - & - & $\begin{array}{l}\text { PCN EF; TT; } \\
\text { PCN+ }\end{array}$ & $\mathrm{x}$ & $\mathrm{x}$ & $\begin{array}{l}\text { Versões: } 1^{\text {a }} \\
3^{\text {a }} ; \mathrm{EM}\end{array}$ \\
\hline Cidadania & $\mathrm{x}$ & $\mathrm{x}$ & $\mathrm{TT}$ & - & $\mathrm{x}$ & - \\
\hline Diálogo & - & - & PCN EF; TT & - & - & - \\
\hline Direito à saúde & - & - & $\mathrm{TT}$ & - & $\mathrm{x}$ & - \\
\hline Ética & - & - & $\mathrm{PCN}+$ & - & - & Versão: $1^{\mathrm{a}}$ \\
\hline Parceria & $\mathrm{x}$ & $\mathrm{x}$ & TT & - & $\mathrm{x}$ & - \\
\hline Protagonismo & - & - & PCN EF; TT & $\mathrm{x}$ & - & $\begin{array}{l}\text { Versões: } 1^{\mathrm{a}} \text {; } \\
2^{\mathrm{a}} ; 3^{\mathrm{a}} \text {; final }\end{array}$ \\
\hline Qualidade de vida & - & - & PCN EF; TT & - & - & $\begin{array}{l}\text { Versões: } 1^{\text {a; }} \text {; } \\
\quad \text { final }\end{array}$ \\
\hline Respeito & - & - & TT; PCN+ & $\mathrm{x}$ & - & - \\
\hline $\begin{array}{l}\text { Saúde - bem-estar individual e } \\
\text { coletivo }\end{array}$ & - & - & $\begin{array}{l}\text { PCN EF; TT; } \\
\text { PCN+ }\end{array}$ & - & - & Versão: $1^{\mathrm{a}}$ \\
\hline
\end{tabular}

${ }^{\star}$ - = ausente ${ }^{\star *} \mathrm{x}=$ presente

Figura 3. Síntese dos conhecimentos, dos valores e das práticas sociais presentes nos textos de cada documento curricular (continua) 


\begin{tabular}{|l|c|c|c|c|c|c|}
\hline Práticas (P) & LDB & DCN & PCN & OCEM & DCNEB & BNCC \\
\hline Assistência à saúde & $\mathrm{x}$ & - & - & $\mathrm{x}$ & $\mathrm{x}$ & - \\
\hline Autocuidado com o corpo & - & - & PCN EF; EM; TT & - & - & Todos \\
\hline Contextualização & - & - & TT & $\mathrm{x}$ & - & Versão: $1^{\mathrm{a}}$ \\
\hline Investigação & - & - & PCN EM & $\mathrm{x}$ & - & Versão: EM \\
\hline Prevenção & - & - & Todos & $\mathrm{x}$ & $\mathrm{x}$ & Todos \\
\hline Promoção da saúde & - & - & PCN EF; EM; TT & - & $\mathrm{x}$ & Todos \\
\hline Transversalidade & - & - & PCN EF; TT & - & $\mathrm{x}$ & Todos \\
\hline
\end{tabular}

${ }^{\star}$ - $=$ ausente ${ }^{\star *} \mathrm{x}=$ presente

Figura 3. Síntese dos conhecimentos, dos valores e das práticas sociais presentes nos textos de cada documento curricular

Nos documentos curriculares, está estruturado um conjunto de conhecimentos, de valores e de práticas que são direcionados para diferentes atores do sistema educacional. Nele, é possível identificar um direcionamento para o setor educação, enquanto área de formulação e de execução de políticas, para os educadores e estudantes, que são os sujeitos envolvidos com os processos de ensino e de aprendizagem. Estes diferentes atores exercem papeis importantes na implementação e reconfiguração dos currículos.

Para o setor educação, os conhecimentos da saúde são enfatizados como um campo de políticas sociais e de serviços. Tal conhecimento é mais explícito nas DCNEB, as quais enfatizam a necessidade da permanente articulação da educação com outros setores, dentre os quais o setor saúde. Os valores que o setor educação precisa estimular perpassam pela articulação intersetorial, estabelecendo parcerias com vistas à formação integral e cidadã. As práticas dizem respeito ao um conjunto de ações para proteção e manutenção da saúde.

Para os educadores e estudantes, a maioria dos conhecimentos, dos valores e das práticas são equivalentes. Os apontamentos dos documentos direcionam para que os educadores tenham o conhecimento e ofereçam condições e ferramentas necessárias para que o estudante alcance o conhecimento e cultive valores e práticas de modo a preservar a sua saúde, bem como a saúde das coletividades.

Uma síntese das interações KVP, direcionadas para os diferentes atores do sistema educacional, está representada na Figura 4. 

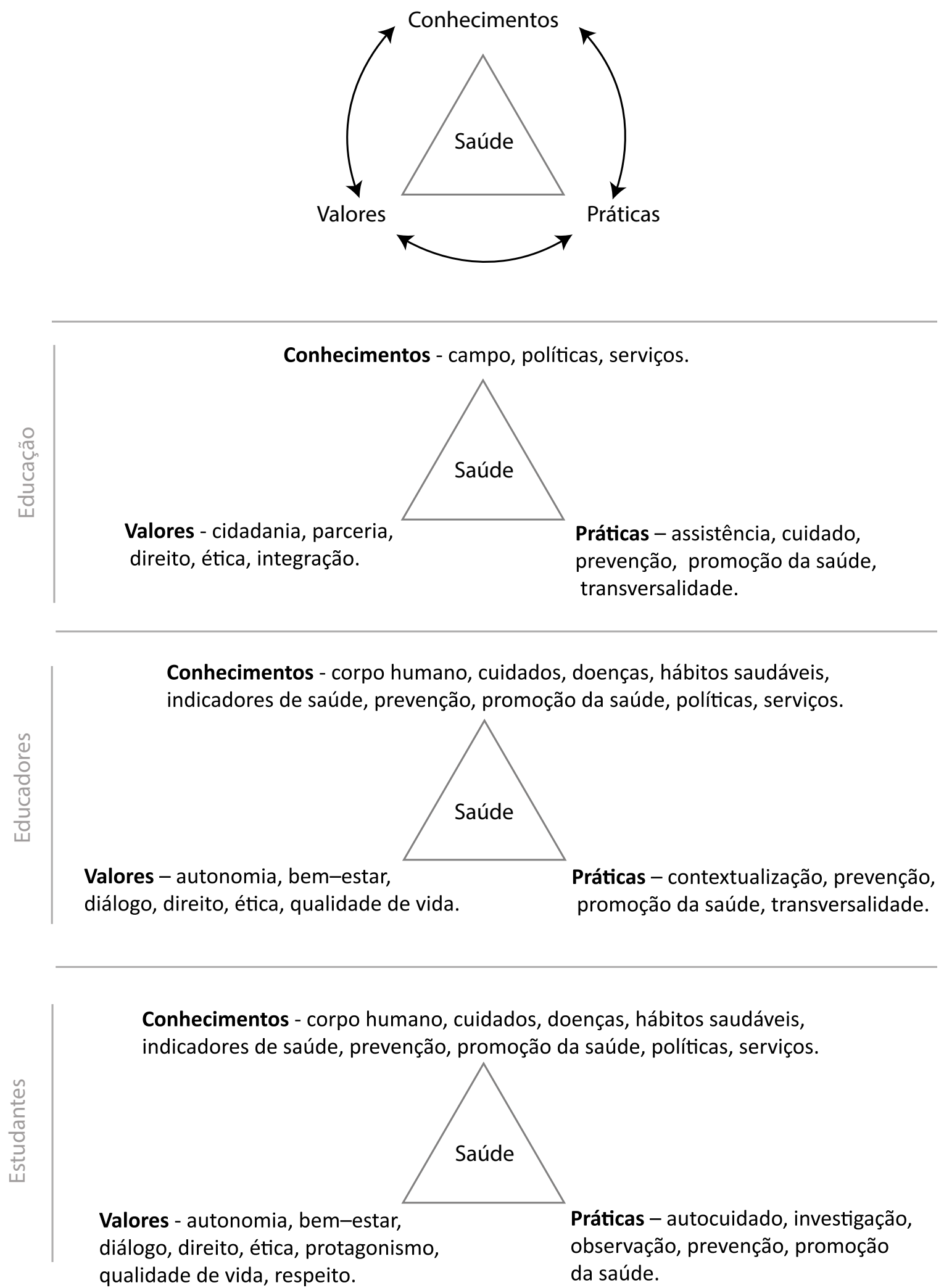

Figura 4. Interações entre conhecimentos, práticas e valores para os diferentes atores do sistema educacional, expressos nos documentos curriculares, baseado no modelo KVP (Clément, 2006) 
Ao interpretar a interação KVP, expressa nos documentos curriculares, de maneira geral, percebe-se que o conhecimento sobre saúde prevalecente está relacionado ao funcionamento do corpo humano; as práticas e as atitudes são direcionadas para o autocuidado e para a prevenção de doenças e riscos; a autonomia e o protagonismo estudantil são valores destacados na maioria dos documentos.

Prevenção e promoção da saúde são termos que surgem em muitos documentos. Enquanto a prevenção de doenças e de riscos é destacada como conhecimentos e como práticas esperadas para todos os atores educacionais, a promoção da saúde apenas é citada, sem especificações das ações promotoras da saúde. A única exceção são os PCN TT Saúde, que trazem as ações esperadas para promover saúde. A determinação social do processo saúde-doença, a equidade em saúde e o conceito ampliado de saúde são categorias e discussões pouco evidenciadas nos documentos, assim como o direito à saúde e o SUS como política pública.

Barbi e Megid Neto (2017) destacam a necessidade da inclusão, nos documentos curriculares oficiais, de elementos problematizadores que possibilitem o entendimento da saúde de maneira multifatorial, que possam contemplar as características das distintas realidades e os diferentes sentidos atribuídos à palavra. De fato, nos documentos há carência de maiores discussões e problematizações em torno do tema, dos aspectos sociais e psicológicos que proporcionam condições objetivas e subjetivas nas percepções e compreensões acerca da saúde.

Da LDB de 1996 à última versão da BNCC, passaram-se 22 anos, período em que ocorreram importantes mudanças políticas e sociais no país. Segundo Apple (2006), o currículo reflete determinado momento histórico e suas relações políticas e sociais. Entretanto, ao identificar as concepções de saúde expressas nos documentos, mesmo no contexto de mudanças das relações políticas e sociais, demonstra-se uma continuidade e repetição daquilo previsto em momentos anteriores, por exemplo, na década de 1990, nos PCN. Lopes (2004), ao realizar análise sobre as políticas curriculares em períodos distintos do governo federal, aponta que estas políticas se mantinham sem rupturas e sem mudanças demarcadas. Sobre os motivos da continuidade, a autora remete ao fato de permanecerem as mesmas concepções sobre educação, mesmo mudando as equipes de gestão.

É certo que os modos de organização e controle da sociedade influenciam a educação e a seleção dos conhecimentos que devem ser valorizados. Especificamente, o currículo tende a selecionar aquilo que interessa a determinada classe social (Apple, 2006). Nesse sentido, nos documentos curriculares analisados, os conhecimentos, os valores e as práticas vinculadas à saúde destacam o funcionamento do corpo humano, as patologias, as práticas de higiene e os hábitos saudáveis, sempre tomando a doença e não a saúde como elemento orientador.

Com fundamento em Clément (2006), que ressalta que os três elementos - conhecimentos $(\mathrm{K})$, valores $(\mathrm{V})$ e práticas sociais $(\mathrm{P})$ - interagem e se influenciam emergindo a concepção. A partir dos documentos analisados, é possível concluir que 
eles mantêm proximidade com uma compreensão de saúde como oposição à doença. Tal concepção, considerada como biomédica, é a que prevalece na sociedade brasileira, e tem sido a ordenadora de muitas políticas, sejam as de atenção à saúde, sejam aquelas voltadas para a educação.

Todavia, é importante salientar que, apesar de as orientações se voltarem para uma cultura individualizada e focada nas doenças, nas atitudes e comportamentos saudáveis, percebe-se, em alguns momentos, certa preocupação, mesmo limitada, em associar saúde às condições de vida das pessoas e a um campo de conhecimento que tem forte ligação com os aspectos educacionais, pautados por uma formação ampla e cidadã. A presença de manifestações desta natureza nos textos analisados dá indícios acerca da necessidade e possibilidade de situar as discussões relativas à saúde a partir de uma concepção mais amplificada.

\section{O lugar da saúde como Direito Social}

Dos documentos analisados, apenas os PCN TT Saúde e as DCNEB apresentam, de forma limitada e superficial, a saúde como um direito social, sendo que o SUS, enquanto política pública de garantia de direito à saúde, se faz presente apenas nos PCN TT Saúde.

Os PCN TT Saúde destacam que os estudantes devem obter a compreensão da saúde como direito de cidadania, valorizando ações voltadas para sua promoção, proteção e recuperação. Embora tais documentos mencionem que o enfoque principal deve estar na saúde e não na doença, quando apresentam os conteúdos sugeridos para a abordagem em sala de aula, estes estão organizados de maneira a dar sentido aos efeitos relacionados ao uso indevido de drogas e às ações de autoconhecimento e autocuidado. Percebe-se forte viés para os comportamentos individuais e pouca ênfase nas políticas públicas que incidem sobre os determinantes e condicionantes da saúde.

Bomfim et al. (2013) destacam que, nos temas transversais, a saúde apresentada como um direito não oferece elementos claros para indicar as responsabilidades do Estado em relação às da sociedade e os meios para garantir esse direito. De fato, em tal documento, mesmo apresentando uma reflexão mais profunda sobre saúde, o direito à saúde não é uma categoria que se destaca, não promovendo um aprofundamento das discussões que favoreça o entendimento das medidas necessárias para assegurar o direito à saúde.

$\mathrm{Na}$ tentativa de identificar nos documentos curriculares as discussões em torno da saúde como um direito, as DCNEB se destacam, ao reforçar a importância dos direitos sociais garantidos constitucionalmente, dentre eles o direito à saúde. Além disto, o documento afirma que a escola está indissoluvelmente ligada ao exercício da cidadania. A versão final da BNCC acena para a importância das políticas públicas, destacando que, ao final do Ensino Fundamental, os estudantes

Devem ser capazes de compreender o papel do Estado e das políticas públicas (campanhas de vacinação, programas de atendimento à saúde da família e da comunidade, 
investimento em pesquisa, campanhas de esclarecimento sobre doenças e vetores, entre outros) no desenvolvimento de condições propícias à saúde” (MEC, 2017, p. 325).

Para compreender o papel do Estado e das políticas públicas, faz-se necessário envolver os aspectos da Política no ensino, aqui em particular, na Educação Científica, uma vez que a ciência escolar não está isenta de valores voltados para determinados interesses. Sendo assim, a relevância social do direito à saúde e do SUS, bem como a compreensão do papel do Estado na garantia desse direito podem ser fomentadas, tendo como pressuposto o letramento científico crítico para o desenvolvimento de ações sociopolíticas (Hodson, 2013; Reis, 2014). Todavia, o direito à saúde e as políticas de saúde são categorias que estão à margem das discussões nos documentos curriculares. Desse modo, há indícios de desinteresses de que o conhecimento político da saúde seja manifesto no currículo, uma vez que o currículo, também, se revela como uma relação de poder (Silva, 2010), em que certos conhecimentos são selecionados e legitimados para fins de ensino e de aprendizagem (Lopes, \& Macedo, 2011).

A saúde como um direito, tal qual expresso pela CFB de 1988 e na Lei Orgânica da Saúde, surge de uma concepção ampliada de saúde e que não se limita à existência dos serviços de saúde. Esse direito implica, também, na garantia de outros direitos básicos, como educação, saneamento básico, segurança, moradia, atividades culturais, dentre outros (Constituição Federal de 1988, 1988; Paim, 2008). Do ponto de vista do acesso às ações e aos serviços de saúde, a criação do SUS está diretamente relacionada à garantia do direito à saúde. Nesse sentido, abordar a saúde como um direito e o SUS como uma política estruturada para garantir esse direito é importante e, consequentemente, desejável que isto esteja presente no currículo prescrito.

\section{Conclusões e Implicações}

A presente análise revela que os documentos curriculares tratam a saúde de forma limitada, centralizando-a nos aspectos biológicos do corpo humano, nos comportamentos individuais, nas doenças e nos riscos. De maneira geral, o currículo oficial, em um período que compreendeu 22 anos, aproxima-se mais de uma concepção biomédica da saúde do que de uma compreensão sistêmica.

Para a área das Ciências da Natureza, os componentes Ciências e Biologia são os preferencialmente eleitos para trabalhar o tema. A transversalidade, embora defendida, em termos práticos é pouco evidenciada. A Educação Científica, como elemento que favorece a construção da autonomia e tomada de decisões, revela-se como um processo híbrido nos documentos analisados e, na maioria das vezes, prevalece o viés tecnicista, apesar de, em alguns aspectos, sugerir-se a interação entre ciência, tecnologia, sociedade e ambiente.

Reconhece-se que os efeitos do currículo formal nos contextos escolares e das práticas pedagógicas dependem de muitos aspectos. Todavia, há que se admitir que os caminhos indicados pelas políticas curriculares certamente influenciam as concepções de saúde expressas no ensino de modo geral. Por isso, é relevante que a concepção 
da saúde nesses documentos ultrapasse o limiar do biológico e dos comportamentos individuais.

Este trabalho contribui no sentido de ampliar as discussões e reflexões de como o tema saúde é concebido em documentos curriculares - que são documentos orientadores de políticas educacionais, de materiais didáticos e de práticas de ensino. Apesar de existir outros estudos que investigaram a saúde em determinados currículos, consideramos que a análise aqui apresentada fornece uma visão mais ampla e integral, pois investiga o currículo prescrito a partir de um recorte histórico, envolvendo uma área do conhecimento, neste caso, Ciências da Natureza.

Um olhar mais específico para cada componente curricular permitiu verificar as aproximações e os distanciamentos de um conceito mais amplo de saúde e se, de fato, o tema é apresentado de forma transversalizada dentro da área. Assim, na medida em que a presença do tema é problematizada, abrem-se possibilidades para novas (re) formulações do currículo prescrito, do currículo em ação, bem como das pesquisas no campo da Educação em Saúde.

Por fim, cabe ressaltar que os achados deste estudo correspondem a um recorte feito para os textos introdutórios e para os textos da área e dos componentes curriculares de Ciências da Natureza, não devendo estendê-los aos documentos curriculares como um todo. Sugerimos a realização de outros estudos envolvendo as demais áreas para que o conhecimento do fenômeno estudado possa ser ampliado e melhor sistematizado.

\section{Referências}

Almeida-Filho, N. M. (2011). O que é saúde? Rio de Janeiro: Editora FIOCRUZ.

Apple, M. (2006). Ideologia e Currículo. 3. ed. Porto Alegre: Artmed.

Barbi, J. S. P., Megid Neto, J. (2017). A Saúde nos anos finais do Ensino Fundamental: Uma análise de documentos de referência. Ata do XI Encontro Nacional de Pesquisa em Educação em Ciências - XI ENPEC, Florianópolis.

Bardin, L. (2009). Análise de conteúdo. Lisboa: Edições 70, LDA.

Bomfim, A. M., Anjos, M. B., Floriano, M. D., Figueiredo, C. S. M., Santos, D. A., \& Silva, C. L. C. (2013). Parâmetros Curriculares Nacionais: uma revisita aos temas transversais meio ambiente e saúde. Trabalho Educação Saúde, 11(1), 27-52. https://doi.org/10.1590/ S1981-77462013000100003.

Buss, P. M. (2012). Determinantes Sociais da Saúde. In L., Giovanella, S., Escorel, L. V. C., Lobato, A. I., Carvalho, (Orgs.), Políticas e Sistemas de Saúde no Brasil (pp. 121-142). $2^{\text {a }}$ edição revisada e ampliada, Rio de Janeiro: Editora Fiocruz.

Carvalho, G, S., \& Clément, P. (2007) "Biology, Health and Environmental Education for better Citizenship” project: analyses of textbooks and teachers' conceptions from 19 countries. Revista Brasileira de Pesquisa em Educação em Ciências, 7(2), 1-21. 
Carvalho, G. S., Clément, P., \& Berger, D. (2008). Educação para a saúde: concepções de professores de 16 países europeus, africanos e do próximo oriente. In J., Bonito (Org.) Educação para a saúde no século XX: teorias, modelos e práticas. Actas do Congresso Nacional de Educação para a Saúde, Évora, 527-540.

Clément, P. (2006). Didactic Transposition and KVP Model: Conceptions as Interactions between Scientific knowledge, Values and Social Practices. Proceedings of ESERA Summer School, IEC. Braga, Portugal, 9-18.

Clément, P. (2010). Conceptions, représentation sociales et modele KVP. Skholê, 16, $55-70$.

Constituição Federal de 1988.(1988). Brasília: Presidência da República.

Fertonani, H. P., Pires, D. E. P., Biff, D., \& Scherer, M. D. A. (2015). Modelo assistencial em saúde: conceitos e desafios para a atenção básica brasileira. Ciência \& Saúde Coletiva, 20(6), 1869-1878. https://doi.org/10.1590/1413-81232015206.13272014.

Hodson, D. (2011). Looking to the Future: Building a Curriculum for Social Activism. Sense Publishers.

Hodson, D. (2003). Time for action: Science education for an alternative future. International Journal of Science Education, 25(6), 645-670. https://doi. org/10.1080/09500690305021

Lei n. 9.394, de 20 de dezembro de 1996 (1996). Estabelece as diretrizes e bases da educação nacional. Brasília, DF: Ministério da Educação. Recuperado de http://portal. mec.gov.br/seed/arquivos/pdf/tvescola/leis/ lein9394.pdf

Lei no 8.080, de 19 de setembro de 1990 (1990). Dispõe sobre as condições para a promoção, proteção e recuperação da saúde, a organização e o funcionamento dos serviços. Brasília, DF: Ministério da Saúde. Recuperado de http://www.planalto.gov.br/ ccivil_03/leis/18080.htm

Lopes, A. C. (2004). Políticas curriculares: continuidade ou mudança de rumos? Revista Brasileira de Educação, 26, 109-118. https://doi.org/10.1590/S1413-24782004000200009 Lopes, A. C., \& Macedo, E. (2011). Teorias de Currículo. São Paulo: Cortez.

Macedo, E. (2006). Currículo: Política, Cultura e Poder. Currículo sem Fronteiras, 6(2), 98-113.

Marinho, J. C. B., \& Silva, J. A. (2015). Concepções e implicações da aprendizagem no campo da educação em saúde. Revista Ensaio Pesquisa em Educação em Ciências, 17(2), 351-371. https://doi.org/10.1590/1983-21172015170204 
Marinho, J. C. B., Silva, J. A., \& Ferreira, M. (2015). A educação em saúde como proposta transversal: analisando os Parâmetros Curriculares Nacionais e algumas concepções docentes. História, Ciências, Saúde - Manguinhos, 22(2), 429-443. http://dx.doi. org/10.1590/S0104-59702014005000025

MEC (2018). Base Nacional Comum Curricular. Ensino Médio. 2018. Brasília: Secretaria de Educação Básica. Recuperado de http://basenacionalcomum.mec.gov.br/bnccensino-medio

MEC (2017a). Base Nacional Comum Curricular. Terceira versão. Brasília: Secretaria de Educação Básica. Recuperado de http://basenacionalcomum.mec.gov.br

MEC (2017b). Base Nacional Comum Curricular. Versão final. Brasília: Secretaria de Educação Básica. Recuperado de http://basenacionalcoum.mec.gov.br

MEC (2016). Base Nacional Comum Curricular. Segunda versão revista. Brasília: Secretaria de Educação Básica. Recuperado de http://historiadabncc.mec.gov.br/\#/site/ inicio

MEC (2015). Base Nacional Comum Curricular. Primeira versão. Brasília: Secretaria de Educação Básica. Recuperado de http://historiadabncc.mec.gov.br/\#/site/inicio

MEC (2013). Diretrizes Curriculares Nacionais para Educação Básica. Brasília: Secretaria de Educação Básica. Secretaria de Educação Continuada, Diversidade e Inclusão. Recuperado de http://portal.mec.gov.br/docman/julho-2013-pdf/13677-diretrizeseducacao-basica-2013-pdf/file

MEC (2006). Orientações curriculares para o ensino médio: Ciências da Natureza, Matemática e suas Tecnologias. Brasília: Secretaria de Educação Básica. Recuperado de http://portal.mec.gov.br/seb/arquivos/pdf/book_volume_02_internet.pdf

MEC (2002). Parâmetros Curriculares Nacionais +: orientações complementares aos Parâmetros Curriculares Nacionais - ciências da natureza, matemática e suas tecnologias. Brasília: Secretaria de Educação Média e Tecnológica. Recuperado de http://portal.mec. gov.br/seb/arquivos/pdf/ CienciasNatureza.pdf

MEC (1999). Parâmetros Curriculares para o Ensino Médio. Brasília: Secretaria de Educação Média e Tecnológica. Recuperado de http://portal.mec.gov.br/seb/arquivos/ pdf/blegais.pdf

MEC (1998a). Parâmetros Curriculares Nacionais: Temas Transversais - Saúde. Brasília: Secretaria de Educação Fundamental. Recuperado de http://portal.mec.gov.br/seb/ arquivos/pdf/ciencias.pdf

MEC (1998b). Parâmetros Curriculares Nacionais: Terceiros e quartos ciclos: Ciências Naturais. Brasília: Secretaria de Educação Fundamental. Recuperado de http://portal. mec.gov.br/seb/arquivos/pdf/ciencias.pdf 
MEC (1998c). Diretrizes Curriculares Nacionais para o Ensino Fundamental. Conselho Nacional de Educação. Parecer CEB n. 04/98. Brasília: Câmara da Educação Básica. Recuperado de http://portal.mec.gov.br/cne/arquivos/pdf/PCB0498.pdf

Mohr, A. (2009). Ensino de ciências e biologia e educação em saúde: análise das proposições dos Parâmetros Curriculares Nacionais (Educação Fundamental). In Jofili, Z., \& Almeida, A. (Orgs.), Ensino de biologia, meio ambiente e cidadania: olhares que se cruzam. (p. 119-125). Recife: Editora Universitária da UFRPE.

Mohr, A. (2002). A natureza da Educação em Saúde no ensino fundamental e os professores de ciências. (Tese de Doutorado em Educação). Centro de Ciências da Educação da Universidade Federal de Santa Catarina, Santa Catarina.

Monteiro, P. H. N., \& Bizzo, N. (2015). A saúde na escola: análise dos documentos de referência nos quarenta anos de obrigatoriedade dos programas de saúde, 1971-2011. História, Ciências, Saúde, 22(2), 411-427. https://doi.org/10.1590/10.1590/S010459702014005000028

MS (1986). VIII Conferência Nacional de Saúde. Relatório Final. Recuperado de http:// saude.gov.br/8_conferencia_nacional_saude_relatorio_final.pdf

Paim, J. S. (2012). Modelos de Atenção à Saúde no Brasil. In Giovanella, L., Escorel, S., Lobato, L. V. C., Carvalho, A. I. (Orgs.), Políticas e Sistemas de Saúde no Brasil. (pp. 459-492). 2a edição revisada e ampliada, Rio de Janeiro: Editora Fiocruz.

Paim, J. S. (2008). Reforma sanitária brasileira: contribuição para a compreensão e crítica. Salvador: Edufba, Rio de Janeiro: Editora Fiocruz.

Paim, J. S. (2006) Desafios para a Saúde Coletiva no Século XXI. Salvador, EDUFBA.

Reis, P. (2013). Da discussão à ação sóciopolítica sobre controvérsias sócio-científicas: uma questão de Cidadania. Ensino de Ciências e Tecnologia em Revista, 3(1), 1-10.

Silva, T. T. (2010). Documentos de identidade: uma introdução às teorias do currículo. $3^{a}$ Ed. Belo Horizonte: Autêntica.

Valadão, M. M. (2004). Saúde na escola: Um campo em busca de espaço na agenda intersetorial. (Tese de Doutorado em Saúde Pública). Faculdade de Saúde Pública da Universidade de São Paulo, São Paulo.

Venturi, T., \& Mohr, A. (2013). Análise da Educação em Saúde nos Parâmetros Curriculares Nacionais a partir de uma nova perspectiva. Atas do IX Encontro Nacional de Pesquisa em Educação em Ciências - IX ENPEC.

World Health Organization. (1948). First International Conference. 1948. 
Marta Caires de Sousa

${ }^{\circ}$ https://orcid.org/0000-0001-9200-3812 Universidade Federal da Bahia

Universidade Estadual de Feira de Santana Salvador, Bahia, Brasil mcaires7@gmail.com

Ana Paula Miranda Guimarães

${ }^{\circ}$ https://orcid.org/0000-0001-7409-7368 Instituto Federal de Educação, Ciência e Tecnologia da Bahia Camaçari, Bahia, Brasil apmguima@gmail.com

Amanda Amantes

[1] https://orcid.org/0000-0003-1678-9870 Universidade Federal da Bahia Salvador, Bahia, Brasil amandaamantes@gmail.com

Submetido em 17 de Agosto de 2018

Aceito em 27 de Fevereiro de 2019

Publicado em 05 de Maio de 2019 